\section{Повышение эффективности эксплуатации лесотранспортных машин с использованием ГИС-технологий ${ }^{1}$}

\author{
В. М. Солнышков ${ }^{2}$ \\ Петрозаводский государственный университет
}

\begin{abstract}
АННОТАЦИЯ
Предлагается методика назначения периодичности технического обслуживания, учитывающая характеристики дорог (уклоны, радиусы переходных кривых, покрытие и др.), техническое состояние автопарка предприятия на настоящий момент.
\end{abstract}

Ключевые слова: лесотранспортные автомобили, техническое обслуживание, ГИС-технологи, комплексный показатель.

\section{SUMMARY}

The technique of purpose of periodicity of the maintenance service, taking into account characteristics of roads (Inclinations, radiuses of transitive curves, a covering etc.), a technical condition of a motor-vehicle pool of the enterprise at the present moment is offered.

Keywords: timber truck, maintenance service, GIStechnologies, integrated measure.

На эффективность эксплуатации лесовозной техники оказывает влияние большое количество факторов, к основным из которых можно отнести: возрастной состав, состояние ремонтно-обслуживающей базы, режим работы и др.

На основе анализа, проведенного в АХК «Кареллеспром», было выявлено, что возрастной состав техники находится в пределах 5 - 10 лет (до 5 лет - 26,3\%; 5 - 10 лет - 40,2\%; свыше 10 лет - 33,5\%). При таком возрастном составе автомобилей резко возрастает необходимость в сильной ремонтно-обслуживающей базе на предприятиях. В данный момент техническое состояние ремонтно-обслуживающих баз предприятий лесопромышленного комплекса Карелии не отвечает современным требованиям, на что указывают следующие показатели: средний коэффициент восстановления составляет $8,9 \%$, коэффициенты технической готовности и выпуска автомобилей на линию значительно ниже нормативных. В результате анализа можно сделать следующие выводы:

1. Экономическая база лесозаготовительных предприятий не позволяет существенно обновить лесовозный парк.

\footnotetext{
${ }^{1}$ Работа выполнена под руководством профессора B. С. Сюнёва.

${ }^{2}$ Автор - аспирант кафедры тяговых машин

(C) В. М. Солнышков, 2003
}

2. В связи с этим возникает необходимость в совершенствовании существующей и разработке новой методики проведения профилактических и ремонтных мероприятий для повышения эффективности работы лесовозного парка.

Для решения задачи повышения эффективности эксплуатации лесовозных машин необходим системный подход к данному вопросу. Учитывая многофакторность и сложность причинно-следственных связей оценочных показателей эксплуатации лесовозной машины, можно предположить, что выбор комплексного показателя, наряду с моделированием процесса движения лесовозного автомобиля, позволяет применять системный подход как наиболее гибкий аппарат оценки эффективности использования техники.

В настоящее время предлагается ряд методов выбора периодичности технического обслуживания. При этом в основном используют [4-11]:

$>$ метод определения периодичности ТО по вероятности исправного состояния;

$>$ метод определения периодичности ТО с учетом производительности;

$>$ метод определения периодичности ТО по параметру технического состояния;

$>$ метод определения периодичности ТО по допустимому уровню безотказности;

$>$ метод определения периодичности ТО по допустимому значению и закономерности изменения технического состояния;

$>$ технико-экономический метод;

$>$ метод статистических испытаний.

В настоящее время при исследовании технологии и машин лесозаготовок широкое применение нашел метод имитационного математического моделирования [12]. При использовании этого метода возможно отображение режимов эксплуатации техники посредством проигрывания ситуаций на компьютере. Однако в настоящее время он недостаточно отработан для прикладного использования.

В силу того, что предметом труда является лес, запасы которого распределены на значительных площадях, применение геоинформационных систем (ГИС) наиболее актуально, т.к. с их помощью можно быстро и точно собирать и анализировать большой объем пространственных данных с высокой периодичностью [1].

Учитывая то, что применение новых компьютерных технологий позволит значительно упростит решение задачи выбора периодичности ТО, нами предлагается для увеличения производительности ЛЗП, повышения эффективности работы лесовозного парка и облегчения выбора режимов ТО разработать методику определения периодичности ТО и реализующую ее программу для ЭВМ.

Разработка методики определения оптимальной периодичности ТО с использованием ГИС-технологий предполагает: 
1. Моделирование природно-производственных условий предприятия, на котором предполагается внедрение методики.

2. Создание баз данных по лесовозным автомобилям предприятия, эксплуатируемым в данных лесовозных условиях.

3. Построение имитационной модели движения автомобиля в ходе его эксплуатации в условиях лесосырьевой базы.

4. Разработку методики назначения периодичности TO.

5. Создание программного обеспечения информационно-аналитической ГИС, АРМ инженера лесозаготовительного предприятия «Периодичность ТО», реализующего данную методику.

В модель природно-производственных условий предприятия, на котором предполагается внедрение методики, входят характеристики природно-климатических условий с учетом сезонных колебаний, основные характеристики лесосырьевой базы, ГИС-модель сети лесовозных дорог и дорог общего назначения.

Сложность реализации имитационной модели движения автомобиля в ходе его эксплуатации в условиях лесосырьевой базы заключается в том, что для воспроизведения эксплуатационных режимов движения необходимо постоянно удерживать в надлежащем соответствии заданный закон движения и законы изменения сил сопротивления и движущей силы [2]. Для этого необходимо производить расчеты с малым шагом приращения пути (например, шаг может быть равен радиусу ведущего колеса).

Для оценки состояния лесовозной машины необходимо выбрать критерий с комплексным показателем $y$. В качестве комплексного показателя может быть выбрана производительность машины, мощность двигателя и др.

На основе проведенного анализа наличия и технического состояния лесовозных автомобилей на рассматриваемом предприятии выводится зависимость средней наработки на отказ $X$ от комплексного показателя y. С помощью ГИС-модели сети дорог (по данному маршруту) и характеристик машин, содержащихся в базе данных (БД), определяются основные параметры движения и производительность на каждом элементарном отрезке пути. Элементарные отрезки характеризуются неизменностью по всей своей длине влияющих на движение автомобиля факторов.

Суть методики назначения периодичности ТО сводится к следующему: рассчитав комплексный показатель на каждом элементарном отрезке движения, с учетом направления маршрута движения автомобиля и количества прохождений автомобиля по данному отрезку, рассчитывается средневзвешенный комплексный показатель. Задаются закон наработки до отказа, текущая или нормативная периодичность ТО и рассчитывается вероятность безотказной работы.
Определение периодичности ТО основывается на методе статистических испытаний. Этот метод сводится к имитационному моделированию реальных случайных процессов возникновения отказов в ходе эксплуатации в определенных условиях, что дает возможность ускорить испытания, исключить влияние побочных факторов, резко сократить стоимость экспериментов, провести при необходимости исследования с целью выбора наиболее пригодного варианта. Исходным материалом для моделирования служат как фактические данные, полученные при наблюдении, так и законы распределения случайных величин. Время возникновения отказов, являясь случайной величиной, может характеризоваться различными законами распределения. В теории надежности, для определения количественных характеристик, часто используют следующие распределения: равномерное, экспоненциальное, гамма-распределение, Вейбулла и др.

Наиболее широкое распространение при исследовании надежности систем получило экспоненциальное распределение. Это обусловлено следующим:

$>\quad$ при его использовании получаются очень простые формулы;

$>\quad$ при ограниченном объеме статистического материала о работе системы трудно обнаружить закономерное отклонение от постоянного значения;

$>$ для большинства систем, состоящих из неоднородных элементов, интенсивность отказов системы в целом постоянна.

При экспоненциальном законе распределения моментов возникновения отказов интенсивность отказов является величиной постоянной, т. е.

$$
\lambda(x)=\lambda=\text { const } .
$$

Зависимость между количественной характеристикой надежности в этом случае будет иметь вид:

$$
p(x)=e^{-\lambda \cdot x} .
$$

Используя метод обратных функций, получим:

$$
\ln p(x)=-\lambda \cdot x
$$

где $\lambda=\frac{1}{\bar{x}}$;

$\bar{x}$ - средняя наработка на отказ, которая берется из имитационной модели движения автомобиля в ходе его эксплуатации в условиях лесосырьевой базы.

Тогда расстояние, через которое фиксируется отказ, можно выразить следующим выражением:

$$
x=-\bar{x} \cdot \ln p(x)
$$


где $p(x)=Z(1)$ - равномерно распределенная от 0 до 1 случайная величина.

При определении оптимальной периодичности ТО схема моделирования сводится к следующему. Предварительно назначается на основании имеющегося опыта или наблюдений значение периодичности ТО $l_{i}$. По формуле (4) вычисляется значение $x_{i}$. Пара чисел $x_{i}$ и $l_{j}$ называется реализацией. Если $x_{i}<l_{j}$, то фиксируется отказ. При $x_{i} \geq l_{j}$ фиксируется отсутствие отказа, т. е. выполнение операции ТО. Опыты повторяют многократно и получают оценку вероятности отказа и профилактического выполнения операции. Если при опытах вероятность отказа оказалась больше заданной, то принимают уменьшенную периодичность и повторяют серию опытов.

Для создания программного обеспечения информационно-аналитической ГИС предлагается использовать ряд программных пакетов, таких как MapInfo, MapBasic, Excel и др.

В программной среде MapInfo создаются электронные карты лесосырьевой базы, лесовозных и прочих дорог с разбивкой на элементарные участки, базы данных по автомобилям.

Программное обеспечение на языке MapBasic позволит реализовать имитационную модель движения автомобиля в ходе его эксплуатации в условиях лесосырьевой базы и методику назначения периодичности TO.

Внедрение данной методики и компьютерной программы в практику позволит научно обосновать и значительно упростить процесс выбора периодичности ТО. Кроме того, программа для ЭВМ, реализующая вышеописанную методику, может использоваться для определения: скорости движения на каждом участке, развиваемой мощности двигателя, количества переключений на каждой передаче, что позволит более точно оценивать конструктивное совершенство машин, дать рекомендации по обоснованию конструктивных решений при проектировании, а также рекомендации по выбору марок машин для эксплуатации в конкретных условиях лесосырьевой базы.

\section{СПИСОК ЛИТЕРАТУРЫ}

1. Герасимов Ю. Ю. Информатизация лесного комплекса: обработка и анализ растровых изображений в геоинформационных системах: Учебное пособие / Ю. Ю. Герасимов, С. А. Кильпеляйнен, М. А. Мазуркевич, А. П. Соколов; ПетрГУ. Петрозаводск, 2001. $236 \mathrm{c}$.

2. Нефёдов А. Ф. Расчет режимов движения автомобилей на вычислительных машинах. Киев: Техника, 1970. 172 с.

3. Проников А. С. Надежность машин. М.: Машиностроение, 1978. 592 с., ил.

4. Кузнецов Е. С. Техническая эксплуатация автомобилей: Учебник для вузов. 3-е изд., перераб. и доп. / Е. С. Кузнецов, В. П. Воронов, А. П. Болдин и др. М.: Транспорт, 1991. 431 с.

5. Техническое обоснование и ремонт автомобилей. 2-е изд., перераб. и доп. / А. А. Лудченко, И. П. Сова Киев: Вища школа. Головное изд-во, 1982. 384 c.

6. Ершов Б. В. и др. Техническое обслуживание автомобилей. Киев: Вища школа, 1969. 446 с.

7. Кузнецов Е. С. Техническое обслуживание и надежность автомобилей. М.: Транспорт, 1972. 224 c.

8. Крамаренко Г. В. Техническая эксплуатация автомобилей. М.: Автотрансиздат, 1962. 500 с.

9. Кузнецов Е. С. Режимы технического обслуживания автомобилей. М.: Автотрансиздат, 1963. 247 c.

10. Несвитский Я. И. Техническая эксплуатация автомобилей. Киев: Гостехиздат, 1961. 408 с.

11. Крашенинников Е. М. Техническое обслуживание машин на лесозаготовительных предприятиях. Петрозаводск: Карельское книжное издательство, 1962. $258 \mathrm{c}$.

12. Андреев В. Н., Герасимов Ю. Ю. Принятие оптимальных решений: теория и применение в лесном комплексе. Йоэнсуу: Изд-во университета Йоэнсуу, 1999. 200 с. 